\title{
The Role of Development Aid in Agriculture in the Common Market for Eastern and Southern Africa: A Panel Vector Autoregression Analysis
}

\author{
Grace Gondwe ${ }^{1} \&$ Josue Mbonigaba ${ }^{2}$ \\ ${ }^{1}$ School of Accounting, Economics, and Finance, University of Kwazulu-Natal, Durban, South Africa \\ Correspondence: Grace Gondwe, School of Accounting, Economics, and Finance, University of Kwazulu-Natal, \\ Durban, South Africa. Tel: 41-766-897-418. E-mail: gondwe.g@gmail.com
}

Received: June 23, 2020

Accepted: August 6, 2020

Online Published: September 15, 2020

doi:10.5539/jas.v12n10p28

URL: https://doi.org/10.5539/jas.v12n10p28

\begin{abstract}
This paper assessed the impact of foreign aid on agricultural productivity and growth in the Common Market for Eastern and Southern Africa (COMESA), using panel vector autoregressive methods. The results show a significant unidirectional causality from agricultural growth to foreign aid and thus confirming the theoretical dispositions of the developmental role of foreign aid. However, instead of complementing domestic resources in this regard, the results showed that foreign aid in the sector substitutes government financing, which effectively reduces its effectiveness. A mismatch in government resources and aid allocations to a sub-sector erodes the synergy that should typically exist between donor aid and government expenditure in a sector. A policy shift towards Result-Based (Aid on Delivery) approaches in aid disbursements will be critical to eliminating fungible resources. Misalignment of aid allocations that are inconsistent with the relative importance of subsectors in the sectoral development goals further undermines the potency of aid. A better understanding of the contribution of the various sub-sectors to the overall growth of the agriculture sector will be crucial for equitable resource allocation and enhanced aid effectiveness. Moreover, the higher impact of domestic resources compared to foreign aid calls for policies to increase domestic resource mobilization and a broader focus on reducing aid dependency.
\end{abstract}

Keywords: Foreign Aid, COMESA, Panel Vector Autoregressive, Impulse Response Function

\section{Introduction}

Agriculture continues to be a hinge for sustainable and inclusive growth for most developing countries, mainly due to its economic importance in facilitating industrial growth and economic structural transformation, food security, sustaining livelihoods, and hence, poverty reduction in most of the poor population. FAO (2018) highlights that at least $75 \%$ of the world's extreme poor highly depend on agriculture for their livelihoods and availability of food. Overall, research shows agriculture as the largest employing sector accounting for up to $81 \%$ of total employment in most developing countries and as much as $50 \%$ of their respective export earnings (Kaya et al., 2008). The Common Market for East and Southern Africa (COMESA) is not exempt from these trends as the sector remains indispensable in its growth and development agenda. Agriculture remains key in sustaining livelihoods in most COMESA countries covering between $70 \%$ and $92 \%$ of the total employment in Burundi, DRC, Eritrea, Eswatini, Ethiopia, Madagascar, Malawi, Rwanda, Uganda, Zambia and Zimbabwe and less than $20 \%$ only in Libya and Mauritius (Figure 1). Furthermore, the sector is vital for COMESA's industrial development and export revenue, covering at least $50 \%$ of the raw materials in its industrial sector and accounting for about $65 \%$ of its foreign exchange earnings (Karugia et al., 2012). 


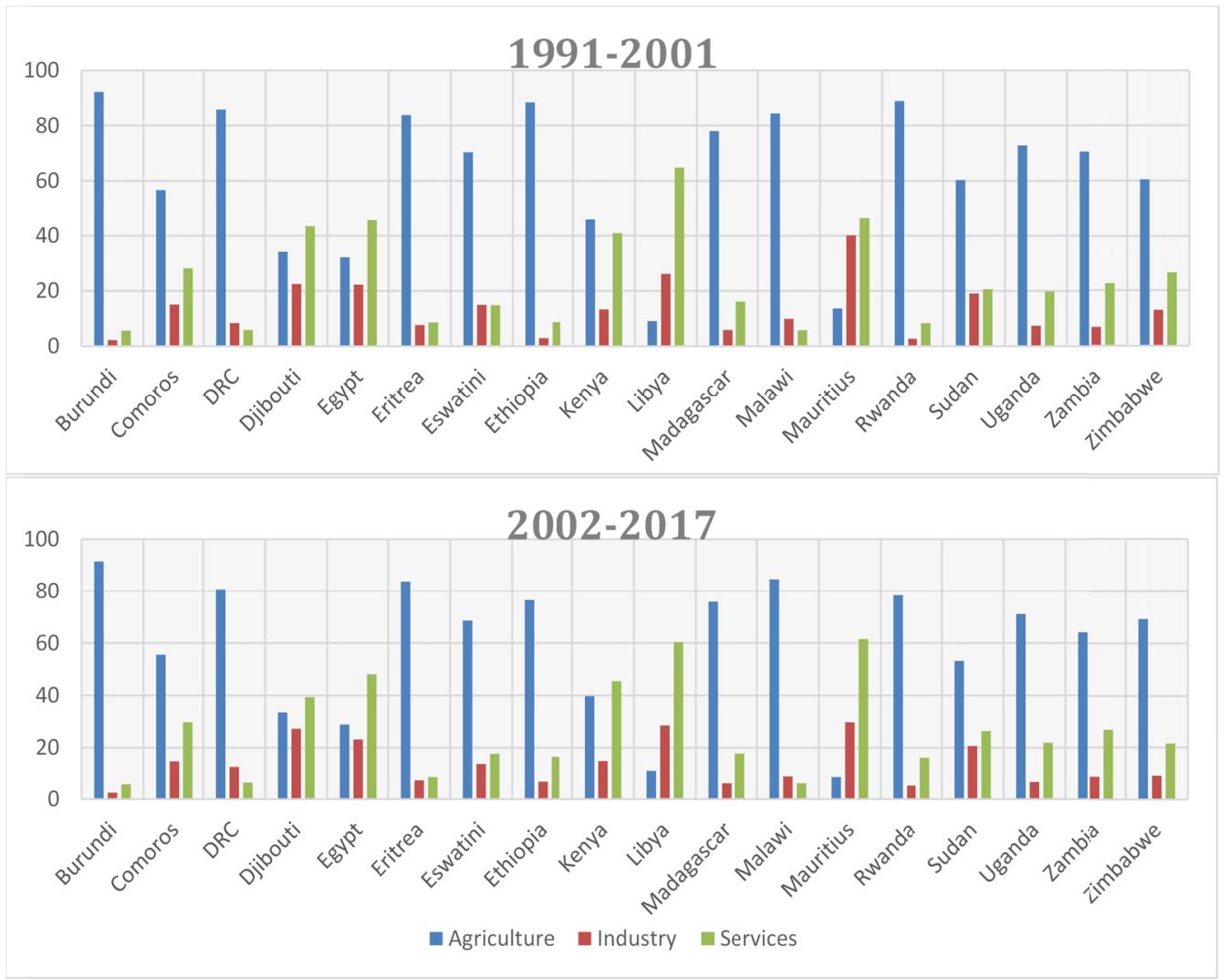

Figure 1. Employment by sector in COMESA countries (2002-2017)

Source: Authors' calculations based on WDI accessed on March 19, 2019.

Despite this central role in the region's trade, industrial development, and sustainability of livelihoods, assessment of data from WDI (2019) shows that agricultural productivity in the region has been persistently low. Its contribution to GDP has been steadily declining over the years in all COMESA countries whose economies largely depend on agriculture. Between 19991 and 2001, Agriculture accounted for 52\% of GDP on average in Ethiopia, about $45 \%$ in DRC and Burundi. It accounted for about $40 \%$ in Rwanda, Sudan, and Uganda. When compared with the 2002 and 2017 period, this has gone down by about 53\% in the DRC, $40 \%$ in Uganda. Similarly, it decreased by about $23 \%$ in Ethiopia and Rwanda and by $26 \%$ in Sudan. The WDI data further shows that the share of the service sector in GDP has continued to increase steadily in these countries. Similar trends are observed in other countries, including Kenya, Madagascar, Malawi, Zambia, and Zimbabwe, whose share in GDP ranges between $16 \%$ and $33 \%$ on average (Figure 2). 


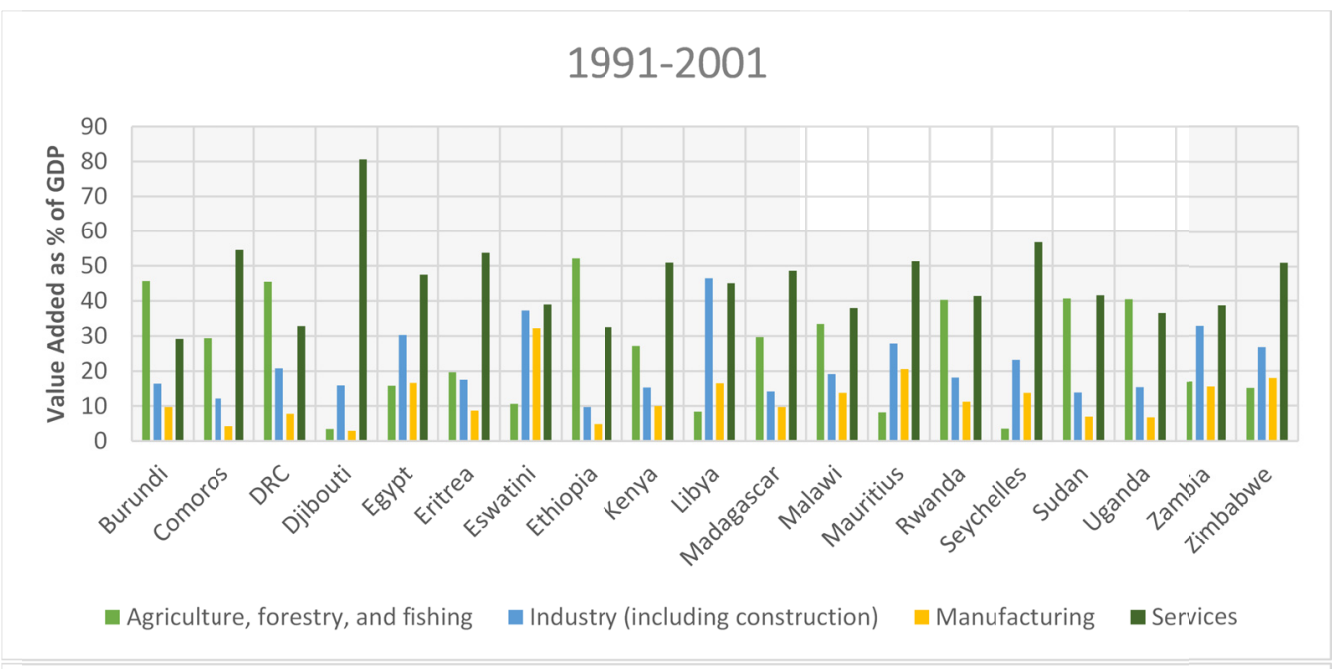

\section{2-2017}

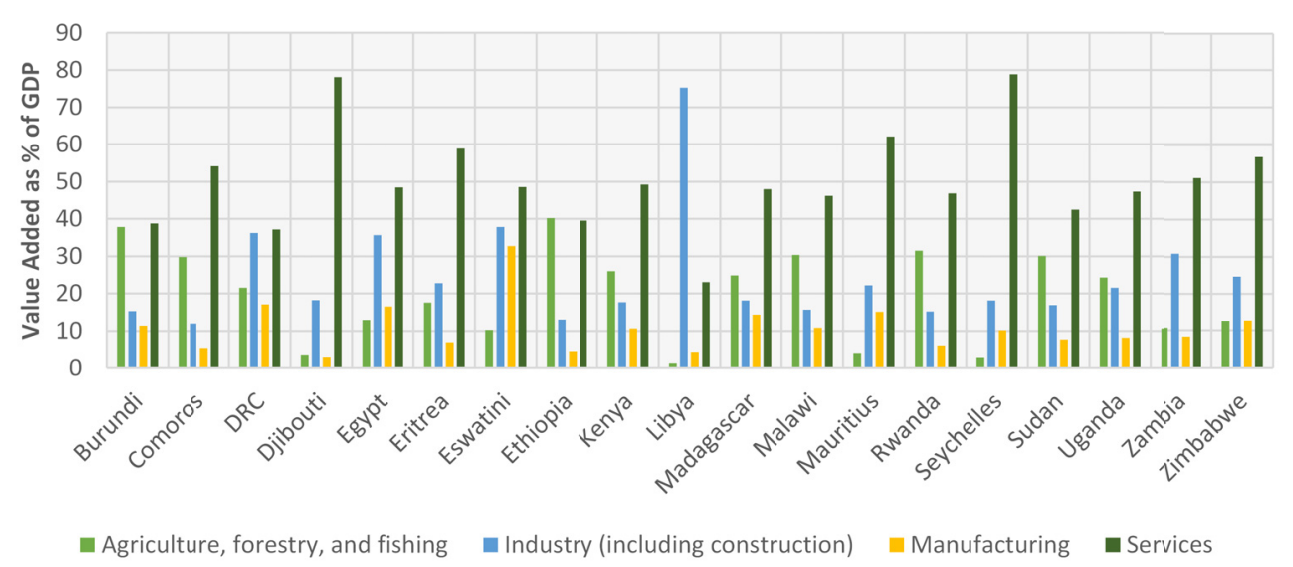

Figure 2. Share of agriculture in GDP in COMESA countries (1991-2017)

Source: Authors' calculations based on WDI and COMSAT data accessed on March 19, 2019.

Although diminishing agricultural share in GDP is not necessarily a bad outcome as it potentially entails desired structural transformation (Note 1) for enhanced growth, it is worth noting that its diminishing influence in GDP is largely being reciprocated by the development and hence, increasing share of services in GDP in most countries. However, contrary to theoretical disposition of a successful structural transformation which entails an invariable decreasing share of agriculture in both GDP and employment as economies develop and industrialize (Mellor, 1961; Soubbotian, 2004; Tran \& Doan, 2010), agriculture has remained the dominant employer in the region covering between 50\%-90\% of the active labour force in 13 of the 19 COMESA countries (Figures 1 and 2). As such, persistent low agricultural productivity in the region entails continued low incomes and high poverty levels on the one hand; dwindling export earnings and overreliance on food imports and food aid on the other hand as their ability to compete on the world market continues to falter (FAO, 2002). Furthermore, it also entails the slow pace of industrialisation (sluggish growth of the industrial sector) due to expensive imported raw materials as the agricultural sector continues to fall short in meeting the industrial sector's demand for raw materials (Karugia et al., 2012). In this regard, boosting the sector's productivity remains imperative for a balanced, sustainable, and inclusive growth process of most COMESA countries. Considering the Sustainable Development Goals (SDGs), this remains key in enhancing (or undermining) the region's ability to achieve SDG1 (Note 2) (Kaya et al., 2008; Christiaensen et al., 2010); as well as SDGs 2 (Note 3) and 8 (Note 4) (AfDB, 2016). 


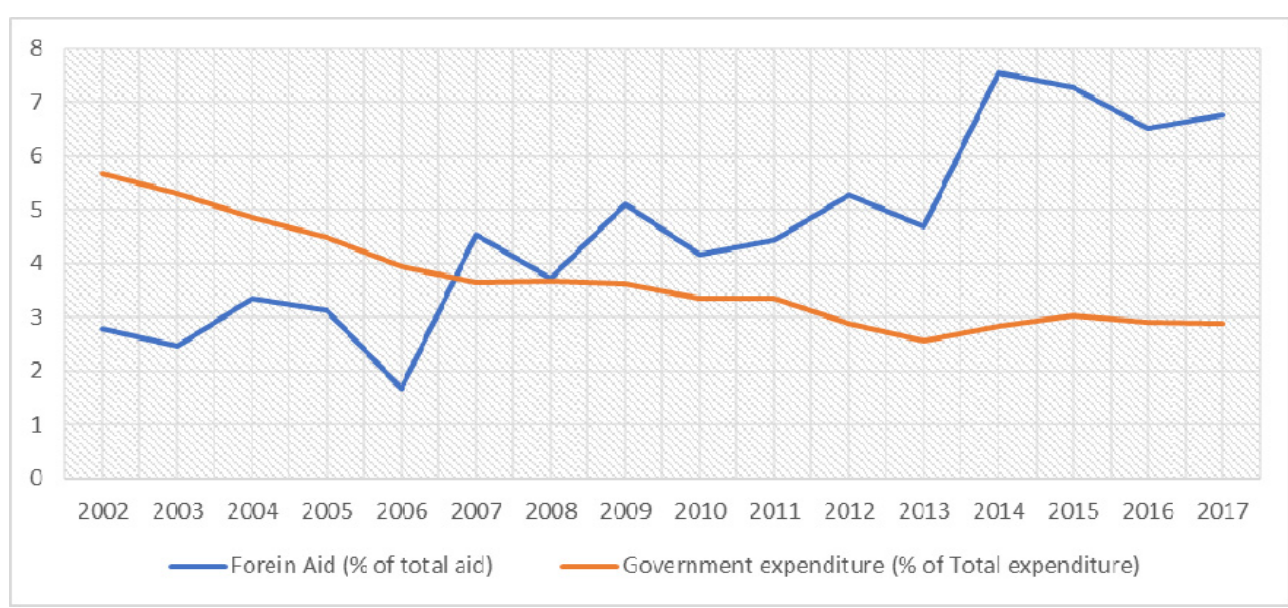

Figure 3. Agriculture Foreign Aid and Government Expenditure in COMESA (2002-2017)

Source: Authors' calculations based on ReSAKSS, 2019, and OECD Stats accessed on March 13, 2019.

While climate variability and climate change shocks are notably having a significant toll on agricultural productivity in most developing countries, recent research highlights the decline in agricultural investment as key in depressing its productivity and growth (Islam, 2011; Alibi, 2014; Ssozi et al., 2017). Recognising this setback vis-à-vis the central role of the sector in its development, African governments through the 2003 and 2014 Maputo and Malabo Declarations, respectively, committed to allocating at least $10 \%$ of their budgets to agriculture. However, most countries in COMESA have not been able to live up to their commitment. Their allocations to the sector continue to be below this threshold. Out of the 19 COMESA countries included in this study, data from ReSAKSS (2019) shows that only Malawi and Ethiopia have consistently met this target at an annual average of $10.2 \%$ and $15.4 \%$ respectively between 2003 and 2008 . These two countries also reached the targets at a yearly average of about $18.9 \%$ and $11.9 \%$, respectively, between 2008 and 2014 . For the rest of the countries, their commitments were lowest $(0.85 \%$ in Djibouti) and the highest ( $8.9 \%$ in Zambia) between 2003 and 2014. Most of these countries fell below the annual average of $4 \%$. Consequently, COMESA, as a region, has not met this target since its initial declaration in 2003. Overall, its commitments barely reached $5 \%$ between 2000 and 2005; and they have continued to decline to less than $4 \%$ on average since 2006 (Figure 3).

Similarly, foreign aid (Note 5) to the sector has been persistently low at around $5 \%$ of the total foreign aid on average at the regional level since 2002. Analysis of data for OECD Stats (2019) shows that only Eswatini, Libya, Madagascar, Malawi, and Rwanda allocated more than $6 \%$ of their total foreign aid annually to agriculture since 2002. Nevertheless, contrary to the decreasing trend in government expenditure at the regional level, Figure 3 highlights that foreign aid to the sector has been increasing, albeit volatile since 2006. This incease in foreign aid raises several issues for the region, such as (i) the effect of foreign aid in the region's agricultural growth and development and (ii) the effect of the prioritisation of foreign aid in the agricultural subsectors in enhancing productivity and growth in the sector.

Against this backdrop, this paper provides the first assessment of the impact of foreign aid on agriculture in COMESA in a Panel Vector Autoregressive (PVAR) framework, which avoids endogeneity instrumentation bias that crowds most aid-growth literature. Covering the period 2008-2017, the focus is on the response path of agricultural productivity and growth to changes in foreign aid; and on the relative role of aid in its sub-sectors. Accordingly, the study intends to unveil pertinent issues behind the current performance of agricultural aid in the region and highlight key future aid investment components for the effective transformation of the sector in the region in its pursuit of sustainable and inclusive growth.

\section{Literature Review}

\subsection{Agriculture and Economic Growth}

Agriculture remains central in economic growth and development due to its rich resource base and viable linkages with other core growth sectors of the economy. This perspective dates to the mid-1950s with the dualist theorists who postulated industrialization of Least Developed Countries (LDCs) as an impossible fit without the support of the agricultural sector mainly through the provision of labour and raw materials to the industrial and service sectors (Lewis, 1954; Fei \& Ranis, 1961). Firstly, they perceived the migration of labour from the 
agriculture sector to support the productivity and growth of the industrial sector with higher incomes/wages in the industrial sector as the main migration drive. Secondly, they visualised increased agricultural productivity and growth as key in meeting the industrial sector's growing demand for raw materials as well as for the food demand of the sector's growing population (Fei \& Ranis, 1961).

Notably, in the dualist model, the growth of the agricultural sector was not a consequence of re-investments from industrial profits but rather a function of labour migration to the industrial sector, which among other things, enhanced agricultural labour productivity over time. However, critics noted that their failure to reckon the importance of reinvesting in agriculture potentially compromises the industrialization of the economy as it effectively limits its ability to support industrial growth and development. As such, Rosenstein-Rodan (1943) and Nurkse (1961) argued for a balanced growth process that encompasses the simultaneous growth of such complementing sectors. Going beyond industrial growth benefits as emphasized by the dualist theorist, they highlighted that the spill-over effects of a balanced growth process on job creation and incomes would be more effective both in expanding the tax base to relieve the fiscal constraint for relevant socio-economic overhead capital. Most importantly, these spill-over effects would create domestic demand for the growing sectors as the incomes/wages in both sectors simultaneously rise. However, despite several criticisms against, such as high unemployment levels in the urban sectors following labour migration (Hossein, 2012), dualist theorists provided a pertinent foundation to the subsequent understanding of agricultural growth and development as an essential component of inclusive and sustainable economic growth.

Subsequently, several studies have been done in the last 2 decades that continue to advocate for agricultural-led economic growth in most LDCs to ensure that the resultant growth process is inclusive and self-sustaining. These include Kaya et al. (2008), who noted that unless economic growth is largely driven by agricultural growth, inclusive growth remains an illusion, especially in countries whose population is largely poor and primarily engaged in agriculture for their livelihoods. Furthermore, Mellor (2001); Rosegrant and Hazell (2001); Christiaensen et al. (2010) contended that agriculture is significantly more effective in ensuring that the poor participate, contribute and benefit from economic growth and development. On the flipside, Ogundipe et al. (2017) found that growth in other sectors (industry and services) does not have a significant influence on the livelihoods of most of the rural poor, notwithstanding their important roles in the overall growth of GDP. Their findings were in line with those of the World Bank (2008), which concluded that the non-agricultural sector-led growth potentially perpetuates the rural-urban income gap as it leaves out most of the rural poor dwellers. In most of these studies, the emphasis has been on the subsistence nature of agriculture in LDCs such that the sector's growth and development have lasting effects on the incomes and livelihoods inter alia of the rural farm population. Furthermore, focusing on its linkages with other sectors of the economy, empirical literature further highlights its role in the self-sustaining growth process of LDCs by enhancing their export earnings and overall national incomes (Johnston \& Mellor, 1961; UNDP \& Odusola, 2017).

The 2030 Agenda for Sustainable Development further underscores the importance of enhancing agricultural growth in LDCs for an inclusive, equitable, and sustainable growth process. With at least $10 \%$ of the global population currently in extreme poverty and highly dependent on agriculture for livelihoods and food (Castañeda et al., 2018; FAO, 2018), it reckons agricultural growth as key in ensuring that the poorest of the poor participate in generating sustainable economic growth and fully share its benefits (SDG 2.3). Accordingly, among other things, it commits to double agricultural productivity and incomes of small-scale subsistence farmers. In meeting this development stride, recent research highlights the need for increased investments in the various components of the sector including land and water resource management to unlock irrigation potential, agricultural research and extension services to enhance adoption of modern technologies and improved inputs; as well as plant/post-harvest loss control (Alibi, 2014; Mellor, 2017).

\subsection{The Role of foreign Aid in Agricultural Productivity and Growth}

As highlighted in Section 1, most developing countries remain financially constrained to meet the financing needs of their agricultural sectors, notwithstanding the sector's indispensable role for the developing countries' inclusive and sustainable growth process. This financial constraint is further quantified through failure by most African LDCs to meet the 2003 Maputo and 2014 Malabo agricultural development investment targets (Alibi, 2014). Therefore, the gap theory advocates for foreign aid as the most viable temporal means of augmenting domestic resources in the respective LDCs for the desired growth outcomes in these LDCs (Chenery \& Strout, 1966). Although studies are confirming this significant role of aid in the agricultural sector growth (Kaya et al., 2008; Akpokodge \& Omojimite, 2008; Alibi, 2014; Verter, 2017; Ssozi et al., 2018), a few studies such as that by Ighadaro and Nwaogwugwu (2013) have concluded otherwise. Among other things, these contradictions highlight the potential of misleading results on the developmental role of foreign aid, mainly owing to the choice 
of estimators. Largely, this follows inconsistencies on the causal relationship between aid and growth in the empirical models. Backed by theoretical propositions that economic growth and development objectives determine the direction of foreign aid flows, aid has been endogenously treated in several aid-growth studies (Gomanee et al., 2005; Moreira, 2005; Clemens et al., 2011). However, aid is among the exogenous variables in another strand of research which believes that the expected developmental role of foreign aid is of minimal importance in determining its allocations which are largely a function of the donors' political and strategic interests (Boone, 1996; Faye \& Niehaus, 2012; Quian, 2014). In other words, different assumptions on aid endogeneity lead to the adoption of different estimators, which potentially leads to different conclusions, especially if wrong assumptions are made ceteris paribus.

For instance, Akpokodge and Omojimite (2008) adopted the two-stage least square (2SLS) estimator, which provides consistent estimates in the presence of endogenous variables. They found a positive influence of foreign aid on agricultural growth in Nigeria, although they failed to ascertain the theoretical propositions that the level of savings (development financing gaps) determines the direction of foreign aid. On the one hand, Ighadaro and Nwaogwugwu (2013) equally assumed endogeneity in their model but opted for the Autoregressive Distributed Lag (ARDL) and Error Correction Model (ECM) which produces reliable long-run estimates even in the presence of endogenous variables (Inder, 1993; Morrissey et al., 2006; Nkoro \& Uko, 2016). However, their study failed to support the findings that foreign aid has a positive influence on agriculture in Nigeria. On the contrary, Verter (2017) confirmed the positive effect of aid on agricultural growth in Nigeria despite failing to support the assertion of aid endogeneity in his model. These and other studies with conflicting results on the same countries potentially misinform aid policy, and as such, the choice of estimators must be carefully done with necessary robustness checks conducted for effective policy inferencing.

\section{Methodology}

Guided by the neoclassical growth model, the production function for agriculture can be specified as $\mathrm{Y}=\mathrm{AF}(\mathrm{K}, \mathrm{L}, \mathrm{N})$ where, $\mathrm{Y}$ is agricultural value-added, $\mathrm{A}$ is total factor productivity (technology), $\mathrm{K}$ is capital, $\mathrm{L}$ is labour, and $\mathrm{N}$ is land. By efficiently financing any of these factors of production, foreign aid can be instrumental in enhancing agricultural productivity and growth. As mentioned above, getting reliable estimates of aid impact in the sector depends on the choice of an estimator. This study reckons the potential of aid endogeneity on the assumption that development resource gaps, as reflected by low savings and growth rates in the recipient economies, determine the direction of foreign aid. Thus, the study employs Panel Vector Autoregression (PVAR) (Note 6) method, which reckons all its variables as endogenous and uses their lagged values as instruments for endogeneity. While noting the importance of accounting for dynamic interdependencies in a panel setting, PVAR also allows for individual heterogeneity in its sample. This technique is specifically preferred because it takes care of aid endogeneity in the model and allows for the impulse response functions (IRF) (Note 7) and forecast error variance decomposition (FEVD) (Note 8) analyses. These provide a chance to study the response of agricultural productivity and growth to a change in foreign aid, which is not possible with most estimators.

Assuming a first-order VAR, this study estimates the following PVAR model:

$$
\mathrm{Y}_{\mathrm{it}}=\beta_{0}+\beta_{1} \mathrm{Y}_{\mathrm{i}, \mathrm{t}-1}+\alpha_{\mathrm{i}}+\varepsilon_{\mathrm{it}}
$$

where, $Y_{i t}$ is a four-variable vector: lnAgriVA or lnagriVA/W, lnODAagri, lnODArural, and lngov. InAgriVA is the natural $\log (\ln )$ of agricultural value-added as a proxy of agricultural growth, AgriVA/W (Note 9) is the agricultural value-added per worker as a proxy of agricultural productivity, ODAagri is the total ODA to the agricultural sector, ODArural is the total ODA for rural development, and govagri is the total public expenditure in agriculture in the agricultural sector, $i$ represent country, $t$ is the time variable. $\alpha_{i}$ is fixed effects variable capturing individual heterogeneity in the model. $\varepsilon_{i t}$ is the idiosyncratic error term.

Although the above specification will give the response paths of each of the variables to the shock in the other variables, it should be noted that the focus of this analysis is on the responses of agricultural growth and productivity to the impulses in agricultural foreign aid. As highlighted above, the study assumes that the level of development in the sector determines its aid allocations and in turn, foreign aid is meant to enhance its productivity and growth. Similar assumptions of reverse causality are also made for agricultural productivity/growth with government expenditure/rural development foreign aid. It postulates that with high levels of agricultural productivity and growth, the amount of investment needed from these three financing sources to sustain the attained levels will not be as high as what is needed to trigger its development process.

Worth noting is the relative impact of the agricultural sub-sectors to its productivity and growth (Alibi, 2014; Ssozi et al., 2018). Agricultural foreign aid in COMESA is largely skewed towards agricultural development, 
which accounts for an annual average of 32\% of the total foreign aid in the sector. This is followed by investments for land and water resource management, which accounts for an annual average of $17 \%$ of the total foreign aid to the sector. Agricultural policy and administrative management come third with 15\%, and an annual average of $14 \%$ of its total allocation is spent on agricultural research, training, and extension services (Figure 4). While focusing on the overall responses of agricultural growth and development to changes in foreign aid is important in highlighting the relative impact of aid in the sector, assessing how sub-sectoral prioritisation has been affecting productivity in the region is equally imperative in enhancing the potency of future allocations. Therefore, Equation 2 below is estimated using the Allerano-Bond Generalised Methods of Moments (A-B GMM) estimator, which also relies on lagged regressors as instruments for endogeneity.

$$
\operatorname{lng}_{\mathrm{it}}=\beta_{0}+\beta_{1} \operatorname{lng}_{\mathrm{i}, \mathrm{t}-1}+\beta_{2} \operatorname{lnODArural}_{\mathrm{it}}+\beta_{3} \operatorname{lngov}_{\mathrm{it}}+\sum_{\mathrm{j}=1}^{\mathrm{k}} \beta_{\mathrm{j}} \mathrm{X}_{\mathrm{j}, \mathrm{i}, \mathrm{t}}+\alpha_{\mathrm{i}}+\varepsilon_{1 \mathrm{t}}
$$

where, $g$ is the natural log of agricultural value-added (lnAgriVA) or agricultural value-added per worker (lnagriVA/W), $\mathrm{X}$ is a vector of ODA in the agricultural sub-sectors, and the rest of the variables are as defined above. Following inconsistencies in the aid-growth literature, the signs of the aid variables cannot be determined apriori. However, the study expects government expenditure to have a positive impact on agriculture productivity and growth, notwithstanding the fact that factors such as corruption that affect aid potency in the sector potentially have a similar impact on government resources.

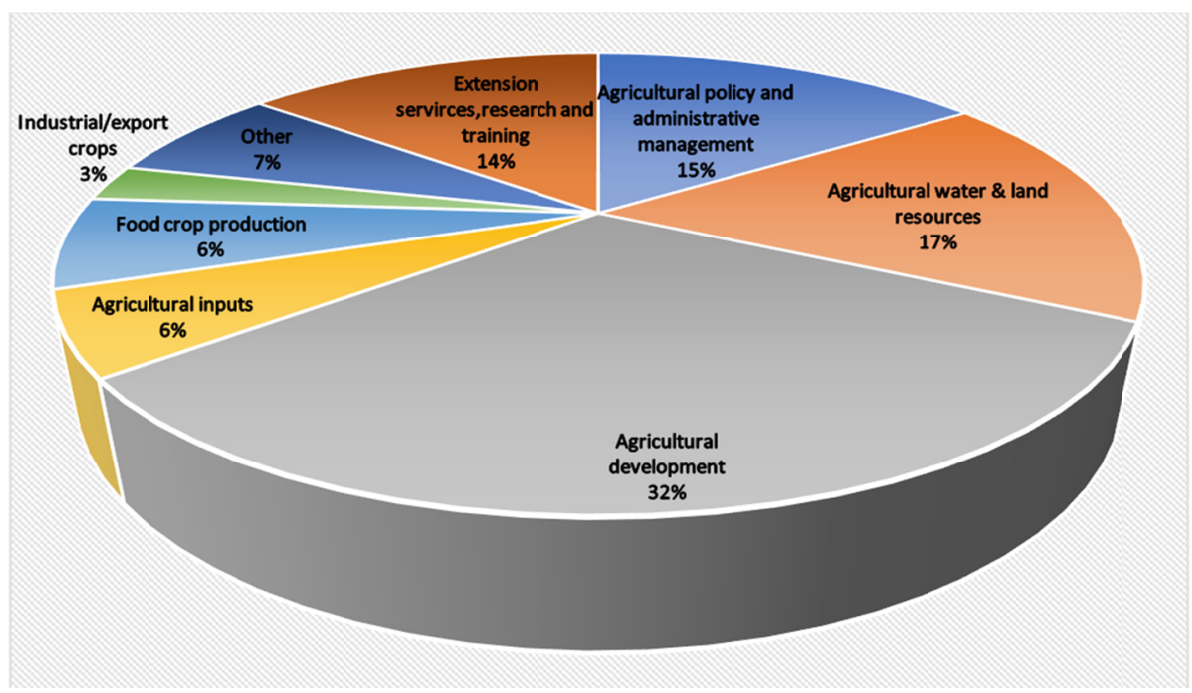

Figure 4. Aggregate Composition of Aid in the agricultural sector in COMESA (2002-2017)

Source: Authors' calculations based on OECD Stats accessed on March 13, 2019.

With most of the resources to the sector disbursed either through the Sector Wide Approaches or Sector General Budget support (SGBS), understanding how institutional quality in the region has contributed to aid potency in the sector is imperative. These resources are mostly cover grants which account for a regional annual average of $67 \%$ since 2002. Coupled with their SGBS disbursement modality and no repayment obligation, grants are generally perceived prone to abuse by the respective recipient governments (Note 16). Therefore, this paper also assesses the relative impact of these forms of aid (loans and grants) in the sector whilst focusing on how institutional quality influences the direction of their impact on the sector's productivity and growth. Proxied by the corruption index from the World Governance Indicators (WGI), the paper estimates the equation below:

$$
\operatorname{lng}_{\mathrm{it}}=\beta_{0}+\beta_{1} \operatorname{lng}_{\mathrm{i}, \mathrm{t}-1}+\beta_{2} \operatorname{lnODArural}_{\mathrm{it}}+\beta_{3} \operatorname{lngov}_{\mathrm{it}}+\beta_{4} \operatorname{lnODA}^{*} \operatorname{corr}_{\mathrm{it}}+\beta_{5} \operatorname{corr}_{\mathrm{it}}+\alpha_{\mathrm{i}}+\varepsilon_{1 \mathrm{t}}
$$

where, corr is the corruption index interacted with total agricultural ODA. ODA in Equation 3 will be further disaggregated into loans and grants to assess how they are affected by corruption. The rest of the variables are as defined above. The paper expects negative signs of the respective aid components interacted with the corruption index with higher levels of corruption in the region.

\section{Data Description and Sources}

The paper utilised secondary data for COMESA countries (Note 10) mainly from the World Development Indicators (WDI), the Organisation for Economic Co-operation and Development (OECD) database, the 
ReSAKSS database, COMESA database; and the African Development Bank (AfDB) socio-economic database (Note 11).

The paper has covered the period from 2008 to 2017, and its key variables are:

(i) ODA as the flow of official grants and concessional loans to developing countries with the main objective of promoting the economic and social development of the recipient economies (OECD, 2018). The focus was on ODA flows to the agricultural sector in the respective COMESA countries. Besides analysing the aggregate flows of foreign aid to the sector and its disaggregation according to type (loans and grants), the paper also looked at its flows to the sub-components in the sector. Some sub-components with related/similar functions were aggregated into the other components due to their low shares in the total foreign aid to the sector. There is also a large share of grants covering up to an annual average of 75\% in most countries between 2002 and 2017. Specifically, seven (Note 12) of the COMESA countries registered zero values for loans throughout the period under study. Zero values were also observed for rural development foreign aid and in the agricultural subsectors. To secure all relevant data points, all the zero values were replaced by an arbitrarily small value of 0.001 , and a $\log$ transformation of all the aid values was utilised in the study.

(ii) Agriculture value added as a proxy for growth in the agriculture sector and Agriculture value added per worker as a measure of productivity in the sector (ReSAKSS, 2019).

(iii) Country score on control of corruption as the extent to which public power is utilised for private gains. The index values vary between -2.5 and 2.5 , with the higher values reflecting lower incidences of corruption (WGI, 2018). For the period under examination, this index was interacted with the various components of aid on the assumption that higher corruption levels in a recipient economy compromise aid potency in infrastructure development.

Overall, data paucity was not a significant issue in this study, as only about $1.2 \%$ missing values spread across a few countries on their government expenditure were noted in the sample. As such, all the estimations were done considering these gaps. However, different values form different data sources for the same data points made dataset choice ambiguous as all data sources that the study utilised are highly credible.

\section{Results and Discussion}

This section presents and discusses the econometric findings of this paper. For the first part of the section that analyses the impact of aid on both agricultural productivity and growth, two models were run, respectively. The second part of the section analyses the sub-sectoral impacts of foreign aid in the sector. Lastly, the third part assesses the role of institutions in aid utilisation focusing on corruption.

\subsection{Preliminary Data Diagnostic}

The choice of an optimal lag order is a critical component of any VAR estimation to avert undermining the credibility of estimates due to factors such as loss of degrees of freedom with the inclusion of too many lags or functional misspecification bias if fewer lags than necessary are considered. To this end, the study adopted the commonly used consistent moment and model selection criterion (MMSC) by Andrews and Lu (2001). Their MMSC is based on Hansen's (1982) $J$ statistic of over-identifying restrictions. These restrictions are analogous to the widely used Bayesian information criteria (BIC), the Akaike information criteria (AIC), the Hannan-Quinn information criteria (HQIC) model selection criteria, They are also referred to as the Modified BIC (MBIC), Modified AIC (MAIC) and Modified QIC (MQIC) respectively.

Table 1. Lag-order selection statistics for Model 1

\begin{tabular}{lllllll}
\hline lag & CD & J & J pvalue & MBIC & MAIC & MQIC \\
\hline 1 & 0.999991 & 46.84925 & 0.520001 & -157.759 & -49.1508 & -92.341 \\
2 & 0.999982 & 25.16199 & 0.799416 & -111.244 & -38.838 & -67.6315 \\
3 & 0.999972 & 15.78702 & 0.467922 & -52.4159 & -16.213 & -30.6097 \\
\hline
\end{tabular}

Table 2. Lag-order selection statistics for Model 2

\begin{tabular}{lllllll}
\hline lag & CD & J & J pvalue & MBIC & MAIC & MQIC \\
\hline 1 & 0.999982 & 48.73618 & 0.443233 & -155.873 & -47.2638 & -90.454 \\
2 & 0.999968 & 27.84777 & 0.676868 & -108.558 & -36.1522 & -64.9457 \\
3 & 0.999972 & 12.33262 & 0.720783 & -55.8703 & -19.6674 & -34.0641 \\
\hline
\end{tabular}


MBIC, MAIC, and MQIC results in Tables 1, and 2 supports the choice the first order PVAR for both models to be estimated (the first model is with agriculture value-added and the second with agriculture value added per worker and henceforth referred to as Model 1 and Model 2 respectively).

\subsection{Empirical Results and Discussion}

Guided by the model selection criterion in Tables 1 and 2, The first order PVARs were run using the forward mean differencing method to remove the country-specific fixed effects (Note 6). Typically, the pvar estimation command in Stata drops all observations with missing data, which entails a loss of data points, and this notably grows with the number of lags included as instruments (Abrigo \& Love, 2016). This meant potentially inconsistent estimates from the model that has missing values and used lags 1 to 4 as instruments. Thus, the estimation utilised the pvar-gmmstyle option in Stata, which minimizes such loss of data points through the replacement of all missing observations with zeros instead of dropping them.

The focus of this section is on the IFRs and FEVD that isolate the impacts of exogenous shocks in each variable on the other variables in the estimated PVAR system. To this end, the study opted for orthogonalized IRFs and their implied FEVDs, which requires that each IRF provides a response path of one variable while holding exogenous shocks in all the other variables in the system constant. It was assumed that agricultural growth and productivity have a direct effect on agricultural foreign aid, ODA for rural development and government expenditure in models 1 and 2 respectively, and that these three variables affected growth and productivity in their respective models only with a lag. In other words, the specification in this study assumes that the level of growth and development determines the direction of both aid and domestic financing in the sector.

The meaningful IRFs and FEVD are conditioned on the stability of the estimated pvars. Specifically, it is postulated that unless the estimated PVAR is stable in that it is invertible with a finite-order vector moving-average (VMA) representation, no meaningful causal relationships can be deduced from its associated IRF (Love \& Zicchino, 2005). In this regard, the Stata pvarstable command was utilised in this study to assess the stability of both models prior to the IRF and FEVD computations in each model using pvarirf and pvarfevd commands, respectively.

Since the focus of the study is on how agricultural productivity and growth responds to the foreign aid-related investments, the explanation of results will be limited to how agricultural productivity and growth responds to the foreign aid-related investments in its core sector and other closely related subsectors, especially rural development. Only relevant highlights for other relationships in the PVAR models will be mentioned. However, the results of all relationships will be provided. First, to be presented and explained are results for Model 1, which will encompass the pvar estimates and all its necessary post estimation results (including stability, IRFs, and FEVD). This is followed by a presentation and discussion of results from Model 2 before drawing unified conclusions from the 2 models.

\subsubsection{Effect of Aggregate Foreign Aid (Loans + Grants) and Government Expenditure on Agricultural} Productivity and Growth

\section{Model 1: Effect of Foreign Aid on Agricultural Growth}

Table 3 indicates that agricultural growth has a large positive effect on the volumes of both agricultural and rural development foreign aid in COMESA, although such an effect on government expenditure appears to be temporal as reflected by the insignificance of the agricultural value-added coefficient on government expenditure. On the other hand, the table shows a marginal and unstable positive influence of agricultural ODA on the sector's growth while government expenditure has a stable positive influence. On the contrary, ODA for rural development has a diminishing effect on agricultural growth in the region. Overall, the causality relationships deduced from Table 3 are simplified in Table 4, which highlights bidirectional causality among all the variables in this model except for a unidirectional causality from agricultural growth to agricultural ODA/government agricultural expenditure. 
Table 3. Estimates for Model 1

\begin{tabular}{|c|c|c|c|c|}
\hline \multirow{2}{*}{ Response of } & \multicolumn{4}{|c|}{ Response to } \\
\hline & ln agva & $\ln$ ODA & ln rural & $\ln$ govt \\
\hline ln agva & $0.90135^{* * *}(0.03396)$ & $0.00055(0.00372)$ & $-0.00450^{* * *}(0.00161)$ & $0.07140^{* * *}(0.01716)$ \\
\hline $\ln \mathrm{ODA}$ & $1.14994^{* * *}(0.39943)$ & $0.23613^{* * *}(0.06626)$ & $-0.03258^{* * *}(0.00701)$ & $0.64994^{* * *}(0.20343)$ \\
\hline ln rural & $2.19787^{* *}(0.04711)$ & $-0.62187^{* * *}(0.11673)$ & $0.39481^{* * *}(0.10526)$ & $-1.69338^{* * *}(0.51263)$ \\
\hline $\ln$ govt & $0.42475(0.29839)$ & $-0.08664^{* * *}(0.02386)$ & $0.03361^{* * *}(0.01229)$ & $0.45580^{* * *}(0.11713)$ \\
\hline
\end{tabular}

Table 4. Granger causality for Model 1

\begin{tabular}{llcc}
\hline Equation/Excluded & chi2 & df & Prob $>$ chi2 \\
\hline lnagva & & & \\
lnoda & 0.02200 & 1 & 0.88200 \\
lnodarural & 7.84500 & 1 & 0.00500 \\
lngovt & 17.31500 & 1 & 0.00000 \\
ALL & 27.74400 & 3 & 0.00000 \\
\hline lnoda & & & \\
lnagva & 8.28800 & 1 & 0.00400 \\
lnodarural & 21.61700 & 1 & 0.00000 \\
lngovt & 10.20800 & 1 & 0.00100 \\
ALL & 106.86800 & 3 & 0.00000 \\
\hline lnodarural & & & \\
lnagva & 4.40600 & 1 & 0.03600 \\
lnoda & 28.38300 & 1 & 0.00000 \\
lngovt & 10.91200 & 1 & 0.00100 \\
ALL & 29.93700 & 3 & 0.00000 \\
\hline lngovt & & & \\
lnagva & 2.02600 & 1 & 0.15500 \\
lnoda & 13.18100 & 1 & 0.00000 \\
lnodarural & 7.47600 & 1 & 0.00600 \\
ALL & 27.24900 & 3 & 0.00000 \\
\hline
\end{tabular}

With all the eigenvalues below 1, the stability test result table and graph in Figure 5 below highlights that the estimated PVAR above is stable and that its estimates can be informatively used in computing both IRF and FEVD.

\begin{tabular}{|c|c|c|}
\hline \multicolumn{3}{|c|}{ Eigenvalue stability condition } \\
\hline \multicolumn{2}{|c|}{ Eigenvalue } & \multirow[b]{2}{*}{ Modulus } \\
\hline Real & Imaginary & \\
\hline .9384124 & 0 & .9384124 \\
\hline .4419752 & -.3245973 & .5483662 \\
\hline .4419752 & .3245973 & .5483662 \\
\hline .1657182 & 0 & .1657182 \\
\hline
\end{tabular}

All the eigenvalues lie inside the unit circle. pVAR satisfies stability condition.

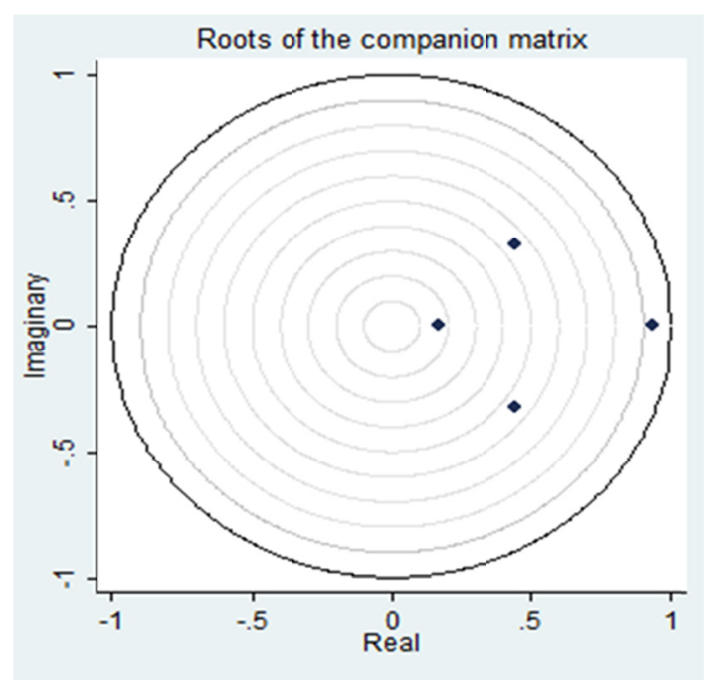

Figure 5. Stability test for Model 1 
Figure 6 shows a marginal and unsustainable response of agricultural growth to exogenous positive shocks in agricultural ODA. Specifically, a one standard deviation increase in agricultural foreign aid results in a marginal positive change in agricultural growth for only about a year and turns into a negative trend with the minimum reached around year 5. This is quantified by the FEVD in Table 5, which shows that a shock in agricultural foreign aid accounts for less than $1 \%$ of the variation in agricultural growth. On the contrary, growth initially decreases marginally following a positive shock in rural development aid in the first year but steadily increases and remains positive from year two until full absorption of the shock around year 5. However, a positive reaction of growth to a change in government expenditure is more persistent, and it decreases smoothly from around year 4. Nevertheless, the impact of a shock in rural development foreign aid on growth in the sector is equally very low at about $1 \%$ from year 5 .

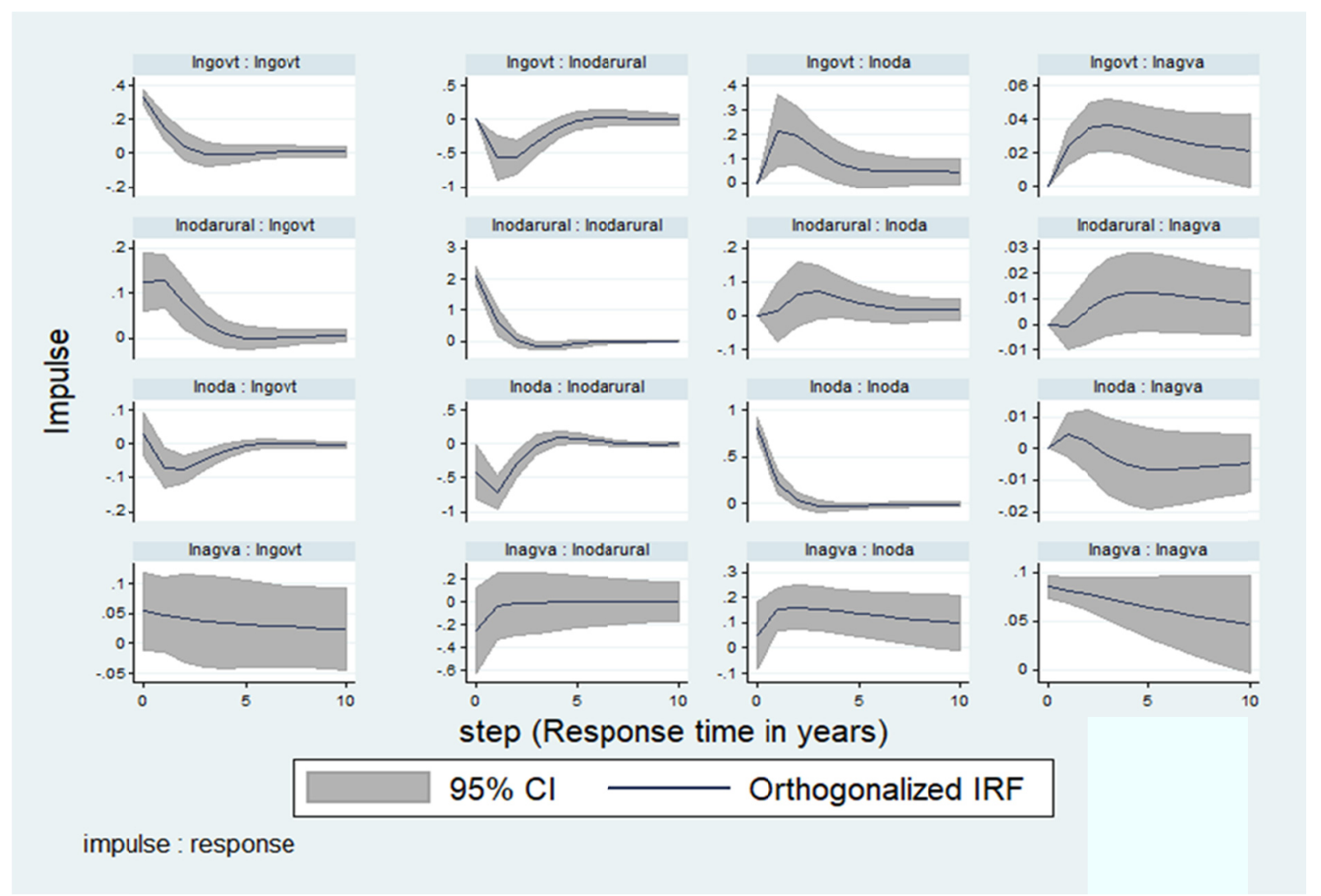

Figure 6. Impulse response function for Model 1

Figure 6 also shows that exogenous changes in growth have large and sustained positive impacts on both agricultural and rural development foreign aid such that a drop in agricultural value added is matched by an increase in foreign aid which, however, steadily declines for agricultural aid and remains relatively stable for rural development aid after about two years. On the other hand, government expenditure shows a marginal steady decline until year 4 , although it is positive throughout the 10 -year period under consideration. 
Table 5. Forecast error variance decomposition for Model 1

\begin{tabular}{|c|c|c|c|c|c|}
\hline \multirow{2}{*}{ Response Variable } & \multirow{2}{*}{ Forecast Horizon } & \multicolumn{4}{|c|}{ Impulse Variable } \\
\hline & & lnagva & lnoda & lnodarural & lngovt \\
\hline \multicolumn{6}{|l|}{ lnagva } \\
\hline & 0 & 0.00000 & 0.00000 & 0.00000 & 0.00000 \\
\hline & 1 & 1.00000 & 0.00000 & 0.00000 & 0.00000 \\
\hline & 2 & 0.95982 & 0.00128 & 0.00003 & 0.03887 \\
\hline & 3 & 0.91554 & 0.00106 & 0.00151 & 0.08188 \\
\hline & 4 & 0.88351 & 0.00096 & 0.00510 & 0.11043 \\
\hline & 5 & 0.86360 & 0.00156 & 0.00881 & 0.12602 \\
\hline & 6 & 0.85198 & 0.00240 & 0.01162 & 0.13400 \\
\hline & 7 & 0.84519 & 0.00311 & 0.01349 & 0.13821 \\
\hline & 8 & 0.84096 & 0.00362 & 0.01471 & 0.14072 \\
\hline & 9 & 0.83805 & 0.00395 & 0.01552 & 0.14247 \\
\hline & 10 & 0.83586 & 0.00419 & 0.01612 & 0.14384 \\
\hline \multicolumn{6}{|l|}{ lnoda } \\
\hline & 0 & 0.00000 & 0.00000 & 0.00000 & 0.00000 \\
\hline & 1 & 0.00379 & 0.99621 & 0.00000 & 0.00000 \\
\hline & 2 & 0.03302 & 0.90759 & 0.00018 & 0.05921 \\
\hline & 3 & 0.06114 & 0.83511 & 0.00499 & 0.09876 \\
\hline & 4 & 0.08451 & 0.79244 & 0.01036 & 0.11269 \\
\hline & 5 & 0.10401 & 0.76656 & 0.01326 & 0.11617 \\
\hline & 6 & 0.12046 & 0.74830 & 0.01439 & 0.11685 \\
\hline & 7 & 0.13441 & 0.73375 & 0.01476 & 0.11708 \\
\hline & 8 & 0.14624 & 0.72141 & 0.01491 & 0.11744 \\
\hline & 9 & 0.15630 & 0.71070 & 0.01501 & 0.11799 \\
\hline & 10 & 0.16490 & 0.70138 & 0.01511 & 0.11861 \\
\hline \multicolumn{6}{|l|}{ lnodarural } \\
\hline & 0 & 0.00000 & 0.00000 & 0.00000 & 0.00000 \\
\hline & 1 & 0.01365 & 0.03730 & 0.94906 & 0.00000 \\
\hline & 2 & 0.01104 & 0.11737 & 0.81776 & 0.05383 \\
\hline & 3 & 0.01036 & 0.12345 & 0.76573 & 0.10046 \\
\hline & 4 & 0.01014 & 0.12084 & 0.75305 & 0.11597 \\
\hline & 5 & 0.01008 & 0.12125 & 0.75088 & 0.11780 \\
\hline & 6 & 0.01006 & 0.12203 & 0.75032 & 0.11760 \\
\hline & 7 & 0.01005 & 0.12227 & 0.75001 & 0.11766 \\
\hline & 8 & 0.01006 & 0.12229 & 0.74989 & 0.11777 \\
\hline & 9 & 0.01006 & 0.12228 & 0.74985 & 0.11782 \\
\hline & 10 & 0.01006 & 0.12228 & 0.74984 & 0.11782 \\
\hline \multicolumn{6}{|l|}{ lngovt } \\
\hline & 0 & 0.00000 & 0.00000 & 0.00000 & 0.00000 \\
\hline & 1 & 0.02288 & 0.00597 & 0.11791 & 0.85324 \\
\hline & 2 & 0.02996 & 0.03383 & 0.17835 & 0.75786 \\
\hline & 3 & 0.03688 & 0.06026 & 0.19571 & 0.70715 \\
\hline & 4 & 0.04323 & 0.06961 & 0.19663 & 0.69053 \\
\hline & 5 & 0.04885 & 0.07094 & 0.19529 & 0.68492 \\
\hline & 6 & 0.05378 & 0.07068 & 0.19425 & 0.68129 \\
\hline & 7 & 0.05810 & 0.07034 & 0.19331 & 0.67826 \\
\hline & 8 & 0.06187 & 0.07000 & 0.19239 & 0.67573 \\
\hline & 9 & 0.06517 & 0.06969 & 0.19158 & 0.67356 \\
\hline & 10 & 0.06805 & 0.06942 & 0.19090 & 0.67163 \\
\hline
\end{tabular}

Notably, the substitution effect of agricultural foreign aid on government expenditure which reflects aid fungibility (Note 13) is persistent in the region. With an increased injection of aid, the government agricultural budget shrinks substantially with its minimum reached around year 2. Despite the turn-around in the third year, 
government financing response to an increase in foreign aid remains negative. Contrary to the theoretical dispositions of foreign aid complementing domestic resources for growth and development, such a trend potentially maintains/widens the existing financing gaps as effectively, net allocations to the sector do not increase by the full amount of foreign aid. This undermines the potency of agricultural aid in achieving its development objectives in the region. Overall, Table 5 highlights that up to about $7 \%$ of the variation in government spending in agriculture is explained by a single shock in ODA which in turn accounts for up to $14 \%$ of the variation in agricultural growth.

Similarly, Figure 6 shows that agricultural foreign aid equally substitutes for foreign aid for rural development and explains up to $12 \%$ variation in foreign aid for rural development within 2 years. Although the response of foreign aid to both these resources is significantly complementary, it is rendered redundant because with such a positive response, the volume of rural development aid and government financing drops; leaving agricultural foreign aid as the key development resource in the sector. As highlighted above, this compromises the potency of agricultural foreign aid despite the significant potential it has in stimulating growth in the sector (Table 3 and Figure 6).

\section{Model 2: Effect of Foreign Aid on Agricultural Productivity}

Although government expenditure, agricultural and rural development foreign aid do not seem to have a meaningful influence on agricultural productivity, Table 6 shows that their direction is largely influenced by agricultural productivity. Specifically, a shock in productivity explains up to $37 \%$ of the variations in agricultural foreign aid, $10 \%$ of the changes in foreign aid for rural development, and as high as $57 \%$ of the variation in government expenditure (Table 8). These causality relationships are further simplified in Table 7, which shows that neither agricultural or rural development, foreign aid nor government expenditure granger causes agricultural productivity, although the opposite holds in the region. Substantiating this trend, the IRF in Figure 8 shows a marginal negative decline in productivity lasting only one period following innovations in rural development foreign aid. Although it stabilises after one period, the response of productivity to a shock in rural development foreign aid remains negative. On the contrary, it marginally increases in the first year and maintains a marginal positive response in the other periods sequel to an increase in foreign agricultural aid. Furthermore, the IRF in Figure 8 shows that labour productivity in the sector relatively remains the same with improvements in government expenditure. None of these investments meaningfully influence variations in agricultural productivity. While a meagre $0.05 \%$ of the variation in agricultural productivity is explained by changes in government financing, only up to $0.3 \%$ of its changes are independently accounted for by agricultural and rural development from year 7 (Table 8).

Table 6. Estimates for Model 2

\begin{tabular}{|c|c|c|c|c|}
\hline \multirow{2}{*}{ Response of } & \multicolumn{4}{|c|}{ Response to } \\
\hline & ln agvaw & $\ln$ ODA & ln rural & ln govt \\
\hline ln agvapw & $0.95515^{* * *}(0.44254)$ & $0.00421(0.70333)$ & $-0.00252(1.61393)$ & $-0.00113(0.45799)$ \\
\hline $\ln$ ODA & $1.88666^{* * *}(0.00520)$ & $0.16976^{* *}(0.07876)$ & $-0.03911^{* * *}(0.11392)$ & $0.30778^{*}(0.02444)$ \\
\hline ln rural & $6.00084^{* * *}(0.00160)$ & $-0.53853^{* * *}(0.01493)$ & $0.06175(0.10271)$ & $-1.10287^{* * *}(0.00905)$ \\
\hline ln govt & $1.39476^{* * *}(0.01805)$ & $-0.08261^{* * *}(0.17774)$ & $-0.01568^{*}(0.40819)$ & $\left.0.46027^{* * *} 0.09490\right)$ \\
\hline
\end{tabular}


Table 7. Granger causality for Model 2

\begin{tabular}{llcc}
\hline Equation/Excluded & chi2 & df & Prob $>$ chi 2 \\
\hline lnagvaw & & & \\
lnoda & 0.65500 & 1 & 0.41800 \\
lnodarural & 2.49300 & 1 & 0.11400 \\
lngovt & 0.00400 & 1 & 0.95000 \\
ALL & 5.38900 & 3 & 0.14500 \\
\hline lnoda & & & \\
lnagvaw & 7.19600 & 1 & 0.00700 \\
lnodarural & 6.85900 & 1 & 0.00900 \\
lngovt & 2.99900 & 1 & 0.08300 \\
ALL & 21.45700 & 3 & 0.00000 \\
\hline lnodarural & & & \\
lnagvaw & 13.82500 & 1 & 0.00000 \\
lnoda & 22.34800 & 1 & 0.00000 \\
lngovt & 7.30000 & 1 & 0.00700 \\
ALL & 40.77700 & 3 & 0.00000 \\
\hline lngovt & & & \\
lnagvaw & 9.27500 & 1 & 0.00200 \\
lnoda & 11.42900 & 1 & 0.00100 \\
lnodarural & 3.00100 & 1 & 0.08300 \\
ALL & 28.94800 & 3 & 0.00000 \\
\hline
\end{tabular}

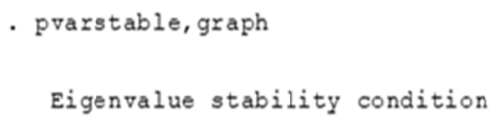

\begin{tabular}{|rr|l|}
\hline \multicolumn{2}{|c|}{ Eigenvalue } & \\
Real & Imaginary & Modulus \\
\hline .9606007 & 0 & .9606007 \\
.358883 & -.0900397 & .3700056 \\
.358883 & .0900397 & .3700056 \\
-.0314375 & 0 & .0314375 \\
\hline
\end{tabular}

All the eigenvalues lie inside the unit circle. pVAR satisfies stability condition.

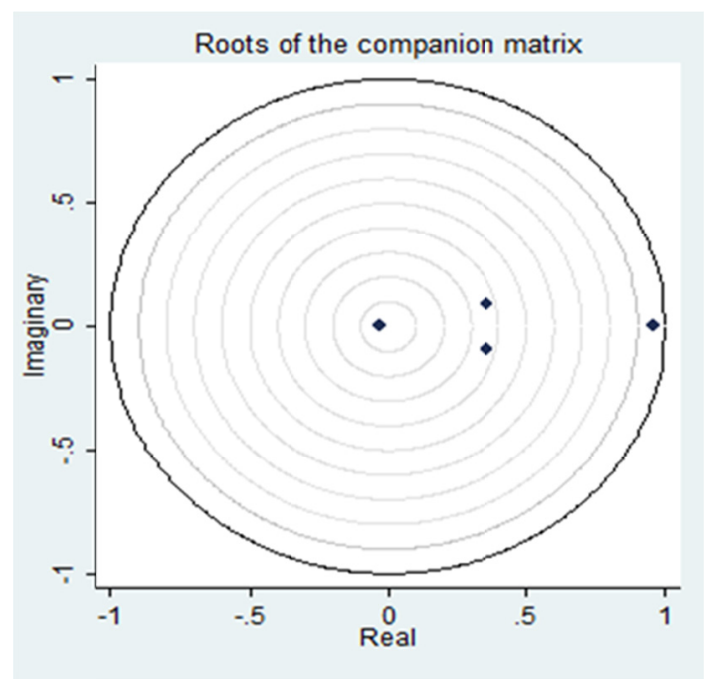

Figure 7. Stability test for Model 2

Figure 7 confirms the reliability of the causality relationships in Model 2. With all eigenvalues below one, the table quantifies by the stability estimated PVAR for Model 2. 


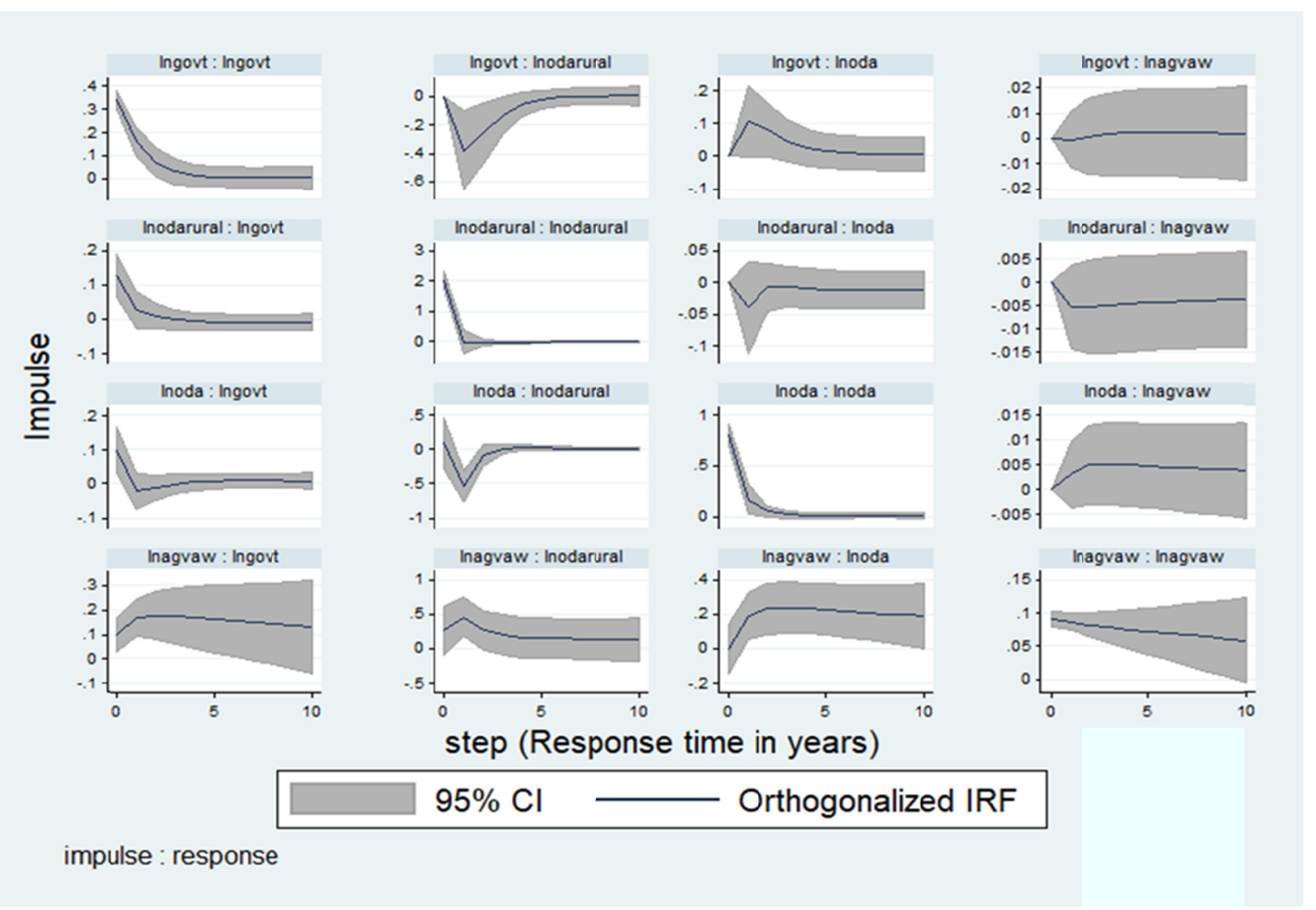

Figure 8. Impulse response function for Model 2

Figure 8 further qualifies the presence of aid fungibility in the region signified by the substitution effect of agricultural foreign aid on government expenditure in the sector. Specifically, a one standard deviation increase in agricultural foreign aid is reciprocated by a sharp decline in government financing lasting about a year before marginally picking in year two and fully absorbing the shock by the end of year two. This trend is well quantified in Table 8 where about $6 \%$ of the variation in government spending is explained by a shock in agricultural foreign aid but such an impact starts faltering in year 2 covering about $5 \%$ in year 2 and continues to drop to about $3 \%$ from year 5 . Similarly, agricultural foreign aid has a significant diminishing effect on aid for rural development. The IRF in Figure 8 highlights a sharp decline in aid for rural development following a unit positive shock in agricultural foreign aid. Unlike the response in government financing, rural development aid significantly drops but bounces back to the original level within two periods following a positive shock in agricultural foreign aid (Figure 8).

Overall, pvar estimates and their associated post estimates confirm theoretical propositions for giving foreign aid that is guided by the need to stimulate growth and development. However, instead of complementing domestic resources in this regard, both models confirm that foreign aid fungibility exists in the sector as foreign aid significantly substitutes government financing in the sector. In other words, the government reduces or increases its financing in the sector following an increase or reduction in foreign aid. Among other things, this has significantly contributed to the marginal and unsustainable impact of agricultural foreign aid on agricultural productivity and growth as net expenditure in the sector and does not effectively increase by the full amount of the disbursed foreign aid. At the centre of this trend are the foreign aid disbursement modalities followed by respective donors, particularly those that limit donor participation in their utilisation.

Guided by the Paris Declaration on aid effectiveness (PD) (Note 14), Sector Wide approaches (SWAPs) or Sector General Budget Support (SGBS) are the most commonly adopted aid disbursement modalities for the sector in the region. These are part of the commonly adopted Programme Based Approaches, which involve the pooling of resources from different donors in the sector into one basket for a shared goal through the recipient government's treasury. Despite earmarking these resources for a specific sector (agriculture in this case), these resources are not project-specific, entailing the recipient government's flexibility in their usage. In most cases, these resources have no conditions except in a few instances where donors require their disbursements only to meet specific 
policy measures. Notwithstanding the benefits of these approaches over project aid, for example (Note 15), SGBS are highly criticised for increased fiduciary risks (Note 16) as the usage liberty given to the recipient government makes them highly fungible (Leiderer, 2012).

Table 8. FEVD for Model 2

\begin{tabular}{|c|c|c|c|c|c|}
\hline \multirow{2}{*}{ Response Variable } & \multirow{2}{*}{ Forecast Horizon } & \multicolumn{4}{|c|}{ Impulse Variable } \\
\hline & & lnagvaw & lnoda & lnodarural & lngovt \\
\hline \multicolumn{6}{|l|}{ lnagvaw } \\
\hline & 0 & 0.00000 & 0.00000 & 0.00000 & 0.00000 \\
\hline & 1 & 1.00000 & 0.00000 & 0.00000 & 0.00000 \\
\hline & 2 & 0.99769 & 0.00059 & 0.00171 & 0.00001 \\
\hline & 3 & 0.99608 & 0.00151 & 0.00237 & 0.00004 \\
\hline & 4 & 0.99508 & 0.00212 & 0.00268 & 0.00013 \\
\hline & 5 & 0.99444 & 0.00249 & 0.00284 & 0.00024 \\
\hline & 6 & 0.99401 & 0.00272 & 0.00293 & 0.00034 \\
\hline & 7 & 0.99371 & 0.00289 & 0.00299 & 0.00042 \\
\hline & 8 & 0.99348 & 0.00300 & 0.00304 & 0.00048 \\
\hline & 9 & 0.99331 & 0.00309 & 0.00307 & 0.00053 \\
\hline & 10 & 0.99317 & 0.00317 & 0.00310 & 0.00057 \\
\hline \multicolumn{6}{|l|}{ lnoda } \\
\hline & 0 & 0.00000 & 0.00000 & 0.00000 & 0.00000 \\
\hline & 1 & 0.00002 & 0.99998 & 0.00000 & 0.00000 \\
\hline & 2 & 0.05020 & 0.93238 & 0.00219 & 0.01523 \\
\hline & 3 & 0.11286 & 0.86281 & 0.00210 & 0.02223 \\
\hline & 4 & 0.17143 & 0.80332 & 0.00201 & 0.02324 \\
\hline & 5 & 0.22132 & 0.75416 & 0.00199 & 0.02254 \\
\hline & 6 & 0.26291 & 0.71352 & 0.00201 & 0.02155 \\
\hline & 7 & 0.29765 & 0.67966 & 0.00206 & 0.02063 \\
\hline & 8 & 0.32692 & 0.65115 & 0.00211 & 0.01982 \\
\hline & 9 & 0.35182 & 0.62690 & 0.00215 & 0.01913 \\
\hline & 10 & 0.37319 & 0.60609 & 0.00220 & 0.01853 \\
\hline \multicolumn{6}{|l|}{ lnodarural } \\
\hline & 0 & 0.00000 & 0.00000 & 0.00000 & 0.00000 \\
\hline & 1 & 0.01685 & 0.00208 & 0.98107 & 0.00000 \\
\hline & 2 & 0.05881 & 0.06254 & 0.84878 & 0.02986 \\
\hline & 3 & 0.07077 & 0.06200 & 0.82487 & 0.04237 \\
\hline & 4 & 0.07739 & 0.06133 & 0.81597 & 0.04531 \\
\hline & 5 & 0.08236 & 0.06106 & 0.81092 & 0.04566 \\
\hline & 6 & 0.08661 & 0.06083 & 0.80703 & 0.04552 \\
\hline & 7 & 0.09043 & 0.06062 & 0.80361 & 0.04534 \\
\hline & 8 & 0.09392 & 0.06041 & 0.80052 & 0.04516 \\
\hline & 9 & 0.09711 & 0.06021 & 0.79768 & 0.04500 \\
\hline & 10 & 0.10004 & 0.06003 & 0.79508 & 0.04486 \\
\hline \multicolumn{6}{|l|}{ lngovt } \\
\hline & 0 & 0.00000 & 0.00000 & 0.00000 & 0.00000 \\
\hline & 1 & 0.06160 & 0.06423 & 0.10420 & 0.76997 \\
\hline & 2 & 0.18228 & 0.04983 & 0.08018 & 0.68771 \\
\hline & 3 & 0.28193 & 0.04303 & 0.06868 & 0.60636 \\
\hline & 4 & 0.35886 & 0.03822 & 0.06101 & 0.54191 \\
\hline & 5 & 0.41732 & 0.03477 & 0.05550 & 0.49241 \\
\hline & 6 & 0.46251 & 0.03223 & 0.05134 & 0.45391 \\
\hline & 7 & 0.49830 & 0.03028 & 0.04808 & 0.42334 \\
\hline & 8 & 0.52724 & 0.02873 & 0.04546 & 0.39856 \\
\hline & 9 & 0.55108 & 0.02747 & 0.04330 & 0.37815 \\
\hline & 10 & 0.57100 & 0.02641 & 0.04150 & 0.36110 \\
\hline
\end{tabular}


On the other hand, there are the Result Based or Aid on Delivery (AoD) approaches, which are also a form of budget support as they are not earmarked for specific projects but are conditioned on the delivery of donor-recipient country mutually agreed specific outcomes that are independently verified. AoD conditions incentivise recipient economies to restrict domestic and aid expenditure on the prioritised investments by focusing on directly linking financing with outputs/outcomes. As such, these approaches are advocated to avert fiduciary risk associated with SWAPs and SGBS. However, research highlights that AoD does not completely deal with aid fungibility, especially in the presence of information asymmetry, particularly where government financing is private to the aid recipient governments. Lederer (2012) shows that recipient governments can opt to declare less resources than what they could comfortably contribute towards the agreed development objectives and redirect these domestic resources to other uses. In which case, foreign aid will continue to substitute for domestic financing, although the degree of such risk is greatly minimised with these approaches vis-à-vis SWAPs, SGBs, and project aid.

Lastly, the results show that foreign aid for rural development has a diminishing effect on agricultural growth in the region. Despite the declining trend and being persistently below agricultural foreign aid (Figure 3), this section shows that the impact of government financing in agriculture is much higher and significant vis-à-vis foreign. It accounts for up to $14 \%$ of the variations in agricultural growth, while foreign aid explains only $0.4 \%$ of its variations.

\subsubsection{Aid Allocation in the Agricultural Sub-sectors}

Having established the response path of agricultural growth and productivity to foreign aid in Section 5.2.1, this section has assessed the relative contribution of agricultural sub-sectoral aid to the sector's productivity and growth. For consistency and comparability of the estimates, the study has continued with the GMM estimation of a first-order PVAR. From the onset of this section, it is worth noting that all the respective variables in both models have similar signs despite their relative differences on the magnitude of their impact and level of significance on growth and productivity.

Table 9. Effect of agricultural sub-sectoral allocations on productivity and growth

\begin{tabular}{|c|c|c|}
\hline \multirow{2}{*}{ Variable } & \multicolumn{2}{|c|}{ Dependent variable and coefficient } \\
\hline & Growth (lnagva) & Productivity (lnagvaw) \\
\hline ln agva L1 & $0.78508^{* * *}(0.0082)$ & \\
\hline ln agvaw L1 & & $0.62423^{* * *}(0.12695)$ \\
\hline In ODA rural for rural development & $-0.01004^{* * *}(0.00286)$ & $-0.00998^{* * *}(0.00257)$ \\
\hline ln govt & $0.02428^{*}(0.01605)$ & $0.01949^{*}(0.01304)$ \\
\hline In policy and administrative management & $0.00234^{* *}(0.00123)$ & $0.00246^{* *}(0.00121)$ \\
\hline In agricultural development & $-0.00559^{*}(0.00335)$ & $-0.00589^{*}(0.00339)$ \\
\hline In water and land resources management & $0.00534^{* *}(0.00243)$ & $0.00649^{* *}(0.00331)$ \\
\hline ln inputs & $0.00029(0.00083)$ & $0.00087(0.00087)$ \\
\hline In food crop production & $0.00053(0.00227)$ & $0.00075(0.00215)$ \\
\hline In industrial crops/export crops production & $-0.00030(0.00269)$ & $-0.00173(0.00230)$ \\
\hline In extension, research and training & $0.00451^{* *}(0.00224)$ & $0.00316^{*}(0.00197)$ \\
\hline lnother & $-.00143(0.00431)$ & $-0.00122(0.00358)$ \\
\hline
\end{tabular}

Confirming Table 3 pvar estimates, the A-B GMM estimates in Table 9 also shows a significant diminishing effect of ODA for rural development on both agricultural productivity and growth. Similarly, it also highlights that increases in government agricultural financing significantly contribute to positive growth outcomes in the sector. With a marginal positive effect of aid on the sector's growth established in Section 5.2.1, Table 9 indicates a positive but insignificant contribution of aid in 3 of the sub-sectors, including inputs, food crop production, while an insignificant negative impact is observed from industrial crop production. Despite being the main recipient of agricultural aid, agricultural development sub-sector shows a significant but negative impact on the sector's growth. Significant and positive impacts are observed from water and land resource management, policy and administrative management; extension, research, and training. These results mainly suggest that the allocation of agricultural foreign aid in its subsectors is not beneficial in maximising its growth-enhancing benefits. 
Firstly, a diminishing effect of agricultural development on the region's growth on the one hand, and incremental benefits on growth from land and water resource management; policy as well as extension services and research, on the other hand, suggest evidence of misalignment of the ODA with the relative importance of the various agricultural sub-sectors. Notably, $32 \%$ of the total foreign aid earmarked for agricultural development annually represents at least double the allocations in each of the other three sectors. In this regard, at least a positive impact on growth could have justified such an allocation otherwise equitably realigning aid to enhance the sector's productivity and growth through increased productive irrigation and enhanced extension systems, for instance, could have been more useful in relation to the sector's sustainable growth.

Secondly, the results highlight insignificant albeit marginal positive effects of aid on growth in all the subsectors that have been receiving an annual average of not more than $6 \%$ of the total agricultural aid (inputs $(6 \%)$, food crops (6\%) and export/industrial crop production (3\%)). Realising that total agricultural aid has been covering an annual average of only about $5.5 \%$ of the total foreign aid in the region from 2008 , the above-average annual allocations to these sub-sectors are quantifiably very low for tangible benefits. However, the relative importance of these sub-sectors in the region's inclusive growth process cannot be overemphasized. While aid for inputs and food crop production is essential for the sector's growth both through increased food security and incomes of the large population of subsistence farmers, aid for industrial/export crop production is key for the region's industrial development and enhanced export earnings (karugia et al., 2012). In this regard, heavily skewing aid allocation towards agricultural development, which has a diminishing effect on the sector's growth at the expense of other potentially beneficial sectors, further suggests evidence of potential misalignment of resources in the sector.

\subsubsection{Effect of Corruption on Agricultural Aid}

Corruption has the expected negative sign and is significant in all the four equations run. However, different signs are obtained when interacted with the aid variables in the models implying its impact on the two components of aid is different. Specifically, the results in Table 10 shows that a marginal impact of the change in corruption is positive on both agricultural productivity and growth, and the volume of grants increases. On the other hand, its impact in the sector is negative, with an increase in loans, although such an effect cannot be statistically confirmed with $10 \%$ level of confidence. This implies that corruption in the sector potentially compromises the potency of loans only and not grants. With at least 7 of the 17 COMESA countries included in this study without the loan component and covering an annual average of only $33 \%$ at the regional level for the entire period under study, the net effect of corruption on aid utilisation at the regional level is the same as that on grants. Thus, overall, the net effect of corruption in the sector is positive, although it is still potentially compromising the utilisation of loans.

Table 10. Effect of corruption on aid effectiveness

\begin{tabular}{|c|c|c|c|c|}
\hline \multirow{2}{*}{ Variable } & \multicolumn{4}{|c|}{ Dependent variable and coefficient } \\
\hline & Growth (lnagva) & & Productivity (lnagvaw) & \\
\hline ln agva L1 & $0.81431^{* * *}(0.06403)$ & $0.79393^{* * *}(0.06617)$ & & \\
\hline ln agvaw L1 & & & $0.72143^{* * *}(0.10625)$ & $0.70559^{* * *}(0.09536)$ \\
\hline ln ODA rural development & $-0.00254(0.00264)$ & $-0.00088(0.00149)$ & $-0.00096(0.00289)$ & $0.001356(0.00209)$ \\
\hline $\ln$ govt & $0.02402(0.02055)$ & $0.01936(0.02219)$ & $0.02354(0.02152)$ & $0.015780(0.02325)$ \\
\hline corruption & $-0.66451^{* * *}(0.20238)$ & $-0.73920^{* * *}(0.27236)$ & $-0.66202^{* * *}(0.16596)$ & $-0.78493^{* * *}(0.22954)$ \\
\hline ln oda*corr & & $0.03488^{* *}(0.01670)$ & & $0.03656^{* * *}(0.01419)$ \\
\hline ln grants*corr & $0.03573^{* *}(0.01492)$ & & $0.03567^{* * *}(0.12222)$ & \\
\hline lnloans*corr & $-0.00620(0.00565)$ & & $-0.00820(0.00670)$ & \\
\hline
\end{tabular}

Note. ${ }^{* * *},{ }^{* *}$ and $*$ indicate significance at $1 \%$, at $5 \%$ and $10 \%$. Robust standard errors in parenthesis.

\section{Conclusion and Policy Recommendations}

\subsection{Summary of Results}

The paper sought to unveil the impact of agricultural foreign aid on agricultural productivity and growth in a PVAR framework. Using the IRFs and FEVD, the focus was on the response path of agricultural productivity and growth to the relative exogenous shocks in foreign aid. The study further assessed how prioritization of aid in the sector affects its potency in enhancing productivity and growth. The study finds a unidirectional causality from agricultural productivity (growth) to foreign aid and thus confirming the theoretical dispositions of the developmental role of foreign aid. However, instead of complementing domestic resources in this regard, the 
results indicate that foreign aid substitutes the government's agricultural financing in the region and thus effectively compromising the potency of aid by the substituted amount. However, a positive and significant coefficient of the grants (total foreign aid) *corruption interactive variable shows that corruption is not compromising aid utilisation in the sector although such negative effects cannot be completely overruled on the utilisation of loans. As such, corruption in the few countries with the concessional loan component potentially increases the fiducial risk associated with the GBS or sectoral support approaches that are commonly used in the region.

Furthermore, the results suggest that the allocation of agricultural foreign aid in its subsectors is not beneficial in maximising its growth-enhancing benefits. The article found that aid in the sector is heavily skewed towards agricultural development, which has a diminishing effect on the sector's growth at the expense of other growth-enhancing sub-sectors, including extension, research, and training as well as water and land resource management. Lastly, the results indicate that foreign aid for rural development has a diminishing effect on both agricultural productivity and growth in the region. Despite the declining trend and being persistently below agricultural foreign aid, the paper found that the impact of government financing in agriculture is much higher and significant vis-à-vis foreign aid. It accounts for up to $14 \%$ of the variations in agricultural growth, while foreign aid explains only $0.4 \%$ of its variations.

\subsection{Policy Recommendations}

The key developmental role of agriculture is achieved through its backward and forward linkages with other relevant sectors in the economy. This is accomplished through its increased productivity and growth to effectively meet the growing demand for raw materials, labour, and income as the economy advances. Among other things, this process demands significant investments to transform the sector and enhance its growth. Despite the low levels of aid allocated to the sector in this regard, marginal impacts of aid on the growth outcomes have been observed mainly owing to aid fungibility and misalignment of aid in its sub-sectors with its growth and development objectives. While misalignment is largely a function of domestic priorities, aid fungibility is potentially seen to be an effect of aid delivery modalities that do not enforce accountability with AoD approaches bearing a very minimal risk of fungibility occurrences vis-à-vis SWAPs, SGBS or project aid. Significantly, the risk of aid fungibility potentially increases with corruption.

Therefore, a comprehensive revision of aid on delivery modalities in the agricultural sector is necessary for the region. Focusing on eliminating fungible resources, COMESA and its development partners should enhance accountability and potency of foreign aid receipts first by adopting Aid on Delivery (AoD) approaches. As shown in Section 5.2.1, future allocations of foreign aid under AoD approaches are strictly a function of a recipient country's achievement of mutually agreed outcomes (Stefan Leiderer, 2012:4). Among other things, this will effectively discourage recipient governments to reduce their counterpart funding as that would entail a mismatch of the planned resources vis-à-vis expected outputs and hence, compromise their ability to deliver on the agreed outcomes. Secondly, COMESA should focus on effectively eliminating corruption in all its member countries to minimise further the risk of misdirecting both foreign aid and domestic resources to non-growth enhancing activities. These should be properly supported by the equitable alignment of the received resources with the sectoral goals.

As such, a thorough understanding of the relative roles of the various agricultural sub-sectors by COMESA remains imperative in guiding its resource allocation for enhanced efficiency in attaining its sectoral development goals. The focus in the respective sub-sectors should be on components with relatively higher positive impacts on productivity and growth. There should be a shift of resource allocation bias from agricultural development to land and resource management to encourage the region's exploitation of its untapped irrigation potential. Funding should be availed to industrial/export crops to encourage diversification of its export base and agro-based industrial growth. COMESA member states should also increase allocations for research, training, and extension services to ensure its adoption of high yielding inputs and advanced agricultural-related technologies. The higher impact of domestic resources on agricultural productivity and growth further suggests the need to cut foreign aid dependency and focus on inward-looking policies for growth. Policies and strategies that focus on increasing domestic revenue would be beneficial in this regard for a self-sustaining growth process.

\section{References}

Abrogo, M. R. M., \& Love, I. (2016). Estimation of Panel Vector Autoregression in Stata: A Package of Programs. University of Hawai'i at Mānoa Department of Economics Working Paper Number 16-2. https://doi.org/10.1177/1536867X1601600314

AfDB. (2016). Feed Africa: Strategy for Agricultural Transformation in Africa 2016-2025. Abidjan. 
Akpokodge, G., \& Omojimite, B. U. (2008). The Effect of Aid Flows on Nigeria's Agricultural Growth. Pakistani Journal of Social Science, 5(6), 514-520.

Christiaensen, L. J., Demery, L., \& Kuhl, J. (2010). The (evolving) role of agriculture in poverty reduction-An empirical perspective. Journal of Development Economics, 96, 239-254. https://doi.org/10.1016/j.jdeveco. 2010.10.006

Clemens, M. A., Radelet, S., Bhavnani, R. R., \& Bazzi, S. (2012). Counting Chickens When They Hatch: Timing and the Effects of Aid on Growth. The Economic Journal, 122(561), 590-617. https://doi.org/10.1111/ j.1468-0297.2011.02482.x

Diao, X., Hazell, P., Resnick, D., \& Thurlow, J. (2007). The Role of Agriculture in Development: Implications for Sub-Saharan Africa. International Food Policy Research Institute (IFPRI) Research Report No. 153.

FAO. (2002). The Role of Agriculture in The Development of Least-Developed Countries and their Integration into the World Economy. Rome, Italy.

FAO. (2008). Ending Extreme Poverty in Rural Areas: Sustaining Livelihoods to Leave No One Behind. Rome, Italy.

Fei, J. C., \& Ranis, G. (1961). A theory of economic development. The American Economic Review, 51(4), 533-565.

Gomanee, K., Girma, S., \& Morrissey, O. (2005). Aid and Growth in Sub-Saharan Africa: Accounting for Transmission Mechanisms. CREDIT Research Paper No. 02/05.

Hayakawa, K. (2009). First Difference or Forward Orthogonal Deviation- Which Transformation Should be Used in Dynamic Panel Data Models? A Simulation Study. Economics Bulletin, 29(3), 2008-2017.

Hossein, H. (2012). Arthur Lewis' Dualism, the Literature of Development Economics, and the Less Developed Economies. King's College, Wilkes-Barre, PA, USA. https://doi.org/10.5539/res.v4n4p132

Ighodaro, C. A., \& Nwaogwugwu, I. C. (2013). Effectiveness of Foreign Aid on the Growth of the Agricultural Sector in Nigeria. Ethiopian Journal of Economics, 22(2), 131-146.

Inder, B. (1993). Estimating long-run relationships in economics: a comparison of different approaches. Journal of Econometrics, 57, 53-68. https://doi.org/10.1016/0304-4076(93)90058-D

Karugia, J., Massawe, S., Guthiga, P., Ogada, M., \& Wambua, J. (2012). Public agricultural expenditures in COMESA, EAC and IGAD: Status and trends. Regional Strategic Analysis and Knowledge Support System, East and Central Africa (ReSAKSS-ECA) Annual Trends \& Outlook Report 2012, Nairobi, Kenya.

Karugia, J., Massawe, S., Guthiga, P., Ogada, M., \& Wambua, J. (2011). Agricultural productivity in the COMESA, EAC and IGAD: status, trends and drivers. Regional Strategic Analysis and Knowledge Support System, East and Central Africa (ReSAKSS-ECA), Nairobi, Kenya.

Kaya, O., Kaya, I., \& Gunter, L. (2008). The Impact of Agricultural Aid on Agricultural Sector Growth. Paper Presented at the Southern Agricultural Economics Association Annual Meeting, Dallas, TX, February 2-6, 2008.

Leiderer, S. (2012). Fungibility and the Choice of Aid Modalities. United Nations University/World Institute for Development Economics Research Working Paper No. 68. https://doi.org/10.2139/ssrn.2362349

Lewis, W. A. (1954). Economic development with unlimited supplies of labour. Manchester School of Economics, 20(2), 139-91. https://doi.org/10.1111/j.1467-9957.1954.tb00021.x

Mellor, J. W. (2001). Faster more equitable growth-Agriculture, employment multipliers and poverty reduction. Agricultural Policy Development Project Research Report 4. Cambridge, MA.

Moreira, S. B. (2005). Evaluating the Impact of Foreign Aid on Economic Growth: A Cross Country study. Journal of Economic Development, 30(2), 25-48.

Morrissey, O., M'Amanja, D., \& Lloyd, T. (2006). Chapter 16 Aid and Growth in Kenya: A Time Series Approach. In S. Lahiri (Ed.), Theory and Practice of Foreign Aid (Frontiers of Economics and Globalization (Vol. 1, pp. 313-332). Emerald Group Publishing Limited, Bingley. https://doi.org/10.1016/ S1574-8715(06)01016-5

Nurkse, R. (1961). Problems of Capital Formation in Underdeveloped Countries. New York: Oxford University Press. 
Regional Bureau for Africa, UNDP, \& Odusola A. (2017). Agriculture, Rural Poverty and Income Inequality in sub-Saharan Africa. ResearchGate Publication \#321625980.

ReSAKSS Database. (2019). Retrieved from http://www.resakss.org

Rosegrant, M. W., \& Hazel, P. B. R. (2001). Transforming the Rural Asian Economy: The Unfinished Revolution. A 2020 Vision for Food, Agriculture, and the Environment (Brief 69).

Soubbotisn, T. (2004). Beyond Economic Growth: An introduction to Sustainable Development. Washington DC: The World Bank. https://doi.org/10.1596/0-8213-5933-9

Tran, T., \& Doan, T. (2010). Industrialization, Economic and Employment Structure Changes in Vietnam during Economic Transition (MPRA Paper \#26996).

Verter, N. (2017). The Impact of Agricultural Foreign Aid on Agriculture in Nigeria. Bulgarian Journal of Agricultural Science, 23(5), 689-697.

World Bank. (2008). World Development Report, 2008. Agriculture for Development, Washington DC.

World Bank. (2019). Agricultural development and economic growth. Retrieved from https://openknowledge. worldbank.org/bitstream/handle/10986/5965/9780195032253_ch05.pdf?sequence=16\&isAllowed=y

\section{Notes}

Note 1. Simply defined as a change in the sectoral composition of output and labour in GDP largely identified by a declining share of agriculture in GDP and employment as the industrial and service sectors gain prominence in this regard.

Note 2. SDG 1 commits to end poverty in all its forms everywhere. Specifically, it commits to eliminate extreme poverty through SDG1.1 and to reduce at least by half the proportion of men, women and children of all ages living in poverty in all its dimension according to national definitions.

Note 3. SGD 2 commits to end hunger, achieve food security and improved nutrition and promote sustainable agriculture.

Note 4. SGD 8 focuses on promoting sustained, inclusive and sustainable economic growth, full and productive employment and decent work for all.

Note 5. In this study, foreign aid refers only to the Official Development Assistance (ODA) as defined by the Development Assistance Committee (DAC) of the Organization for Economic Cooperation and Development (OECD). OECD defines ODA as the flow of official grants and concessional loans to developing countries with the primary objective of promoting the economic and social development of these economies (Führer, 1994; OECD, 2018).

Note 6. The study adopts Stata pvar estimator which estimates the PVAR model by fitting independent regressions for each dependent variable and uses their respective lags and those of the rest of the variables as instruments for endogeneity. The estimator runs on Generalised Methods of Moments (GMM) and we have opted for forward-mean differencing which eliminates fixed effects without generating biased estimates from unbalanced panels as is potentially done by the first-differencing method utilised by most estimators (Love \& Zicchino, 2006; Hayakawa, 2009).

Note 7. IRFs show the response path of one variable to a one-time shock in another variable all other shocks in the PVAR system are held at zero.

Note 8 . FEVD measures the magnitude of variation in one variable explained by the shocks imposed in another variable within a specific forecast horizon.

Note 9. We reckon the limitation of this proxy which is not fully encompassing all inputs in the model as it is mainly capturing labour productivity. As highlighted by Karugia et al. (2011), the total Factor Productivity (TPF) measure which considers all inputs would be ideal but empirically very limited due to data paucity.

Note 10 . With $100 \%$ agriculture value added and agriculture value added per worker missing values for Djibouti and Libya, the two countries were dropped from the sample.

Note 11. http://databank.worldbank.org/data/home.aspx; https://stats.oecd.org/qwids; https://www.resakss.org; http://comstat.comesa.int; http://dataportal.opendataforafrica.org

Note 12. Comoros, Djibouti, Eritrea, Libya, Mauritius, Seychelles and Zimbabwe. 
Note 13. Aid fungibility is generally defined as a state in which categorical aid in the recipient economy has at least one of the following features (i) substitutes for government financing (ii) is used to reduce domestic taxes (iii) diverted to other unintended sectors.

Note 14. Founded on 5 key principles: Ownership, Alignment, Harmonisation, Managing for results, Mutual accountability.

Note 15. Among the benefits of project support include increased funding predictability and hence, manageable development planning; and reduction in transaction costs for the recipient government through unified funding and reporting modalities.

Note 16. The risk that the received aid will end up financing unintended programmed with the worst scenario being benefiting the elite through corruption for example or the risk that the received aid will free up government resources for the benefit of the elite inter alia.

\section{Copyrights}

Copyright for this article is retained by the author(s), with first publication rights granted to the journal.

This is an open-access article distributed under the terms and conditions of the Creative Commons Attribution license (http://creativecommons.org/licenses/by/4.0/). 